\title{
TEORÍA MIMÉTICA Y AMÉRICA LATINA: EL VIGENTE PROBLEMA DE LA IDENTIDAD, UN DIÁLOGO QUE NOS CONVOCA*
}

Fecha de entrega 20170918

Fecha de evaluación 20171002

Fecha de aprobación 20171105

Juan Manuel Díaz Leguizamón**

\section{Resumen}

Este texto busca reflexionar sobre el problema de la identidad latinoamericana mediante la exploración de la propuesta del estudioso brasileño de literatura comparada João Cezar de Castro Rocha, y su fecundo diálogo con la teoría mimética del deseo, desarrollada por el pensador francés René Girard. Rocha viene proponiendo una revisión de la historia cultural de América Latina como instancia de comprensión de la propia identidad, e invita a generar conciencia, con el fin de fortalecerla, de la que él considera la estrategia de producción cultural por excelencia de nuestros pueblos, emanada de su circunstancia no hegemónica: la "poética de la emulación". El examen de esta historia permite acuñar una tipología característica para nuestras culturas como "shakespearianas"; permite trazar líneas de transmisión simbólica, inusitadas y complejas, entre nuestras mentes más destacadas; y visibiliza la presencia de un vocabulario o campo

* Este texto es resultado de la elaboración final de unas notas presentadas por el autor como ponencia en el VI Congreso Colombiano de Filosofía, organizado en la Universidad del Norte, Barranquilla, agosto 10 de 2016. Citar como: Manuel, J. (2018). Teoría mimética y américa latina: el vigente problema de la identidad, un diálogo que nos convoca. Cuadernos de Filosofía Latinoamericana, 39(118), 143-158. DOI: https://doi.org/10.15332/10.15332/s0120-8462.2018.0118.08

** Magister y pregrado en Filosofía de la Universidad Javeriana. Pregrado en historia de la Universidad Nacional de Colombia. Profesor de Filosofía y Arte de la Universidad Javeriana. Ha realizado estudios sobre la música desde G. Deleuze. Correo electrónico: polixetes@hotmail.com. 
semántico especialmente sensible frente a problemáticas propias de la construcción de "interdividualidades colectivas". Además, se convierte en un caso ejemplar de cómo el diálogo con tradiciones aparentemente ajenas puede mostrarse fructífero, relativizando precisamente la engañosa "pureza" de la dicotomía entre lo "propio" y lo "ajeno" y entre lo "original" y lo "copiado".

Palabras clave: mímesis, identidad, literatura comparada, poética de la emulación

\section{Abstract}

This text seeks to reflect on the problem of Latin American identity through the exploration of the proposal of the Brazilian student of comparative literature João Cezar de Castro Rocha, and his fruitful dialogue with the mimetic theory of desire, developed by the French thinker René Girard. Rocha has been proposing a revision of the cultural history of Latin America as an instance of understanding of the identity itself, and invites to generate awareness, in order to strengthen it, which he considers the strategy of cultural production par excellence of our people, emanated from its non-hegemonic circumstance: the "poetics of emulation". The examination of this history allows to coin a characteristic typology for our cultures as "Shakespearean"; it allows to trace symbolic, unusual and complex transmission lines among our most outstanding minds; and it makes visible the presence of a vocabulary or semantic field that is especially sensitive to problems inherent in the construction of "collective interdividualities". In addition, it becomes an exemplary case of how dialogue with seemingly alien traditions can be fruitful, relativizing precisely the deceptive "purity" of the dichotomy between "own" and "alien" and between "original" and "copied".

Keywords: Mimesis, identity, comparative literature, poetics of emulation.

* This text is the result of the final elaboration of some notes presented by the author as a lecture at the VI Colombian Congress of Philosophy, organized at the Universidad del Norte, Barranquilla, August 10, 2016. 


\title{
Resumo
}

Este texto busca refletir sobre o problema da identidade latino-americana mediante a exploração da proposta do estudioso brasileiro de literatura comparada João Cezar de Castro Rocha e seu fecundo diálogo com a teoria mimética do desejo, desenvolvida pelo pensador Frances René Girard. Rocha propõe uma revisão da história cultural da América Latina como instância de compressão da própria identidade e faz o convite para gerar consciência com o objetivo de fortalecê-la, ele considera a estratégia de produção cultural por excelência de nossos povos, emanada da sua circunstância não hegemônica: a "poética da emulação". O exame desta história permite acunhar uma tipologia característica para nossas culturas como "shakespearianas"; permite traçar linhas de transmissão simbólica, inusitadas e complexas, entre nossas mentes mais destacadas; e visibiliza a presença de um vocabulário ou campo semântico especialmente sensível perante as problemáticas próprias da construção de "interdividualidades coletivas". Além, torna-se um caso exemplar de como o diálogo com tradições aparentemente alheias pode mostrar-se frutífero, relativizando precisamente a enganosa "pureza" da dicotomia entre o "próprio" e o "alheio" e entre o "original" e o "copiado".

Palavras-chave: mimese, identidade, literatura comparada, poética da emulação.

\section{Teoría mimética: deseo e interdividualidad}

\author{
Tendremos que reemplazar el "amaos los unos a los otros" por esta doctrina: \\ "Comeros los unos a los otros". Al fin y al cabo, son los dos refranes de la civilización. \\ -Joaquim María Machado de Assis
}

En su libro ¿Culturas shakespearianas? Teoría mimética y América Latina, Rocha declara su deuda con la ${ }^{\circ o o}$ en lo que respecta a una serie de tesis que permiten explicar

* Este texto é resultado da elaboração final de umas notas expostas pelo autor como apresentação no VI Congresso Colombiano de Filosofia, organizado na Universidade do Norte, Barranquilla, agosto 10 de 2016. 
de manera muy potente: 1) los procesos ambiguos de constitución de las identidades individuales y colectivas a través del deseo mimético; 2) el origen de la cultura y su fundamento en la religión, como un sistema de administración de la violencia y lo sagrado, a través de la aplicación del mecanismo de victimización sacrificial conocido como "chivo expiatorio" (Rocha, 2014). Este análisis se concentrará en las relaciones establecidas con la primera de estas tesis, pues es la que más explota Rocha en su trabajo.

La teoría mimética es una formulación altamente paradójica, puesto que descansa en el reconocimiento de la ambigüedad constitutiva y dual, tanto del deseo como de lo sagrado: de su poder tanto generativo/integrador como al mismo tiempo destructivo/ desintegrador.

No solo para Girard, sino también para muchos otros pensadores, en el origen de nuestros comportamientos aprendidos se encuentra la imitación, verdadero fundamento de sociabilidad y condición de posibilidad del proceso de individuación. Aprendemos observando y copiando a otros, reproducimos las acciones, gestos, posturas e ideas de terceros. En nuestras etapas más tempranas exhibimos un impulso muy natural por querer apropiarnos de lo que nuestros otros más próximos tienen, y esto se aviene a un deseo de querer ser como esos otros. Se constata así una inevitable presencia del otro como modelo prestigioso en la constitución de nuestras identidades, pues en la medida en que nos muestra qué desear y cómo hacerlo, lo admiramos. Deseamos objetos sobre todo porque otros los desean y, como efecto de una extraña alquimia, estos se sobrecargan y se vuelven codiciados a nuestros ojos.

De entrada, la comprensión mimética del ser humano se aleja de la idea moderna que describe subjetividades autotélicas, las cuales producen en su interior un deseo que se cree íntimo, propio y espontáneo. El sujeto, tal como lo entiende la teoría mimética, nunca se pertenece del todo a sí mismo. Su identidad es más una “interdividualidad”, pues está atravesado por terceras partes, siempre volcado hacia afuera. El pretendido “egocentrismo", rasgo propio del romanticismo, realmente está contaminado por un "altercentrismo", y esta situación antropológica constitutiva curiosamente fue mejor comprendida en tiempos premodernos, menos signados por nuestros sesgos individualistas.

En la medida en que en las sociedades modernas la distancia entre las personas disminuye -esto debido a circunstancias culturales, políticas, económicas, sociales 
y hasta tecnológicas-nos cuesta más trabajo tener conciencia de la manera como funciona nuestro deseo en el proceso de constitución de nuestra identidad. Para Girard, la imitación de unos y otros la podemos observar fácilmente como un dato objetivo, en el comportamiento ajeno, pero cuesta mucho reconocerla reflexivamente, como dato subjetivo, como una realidad que también nos involucra y en la que caemos presos todo el tiempo. La razón es que la construcción de nuestra identidad descansa sobre un deseo de diferenciación.

La teoría no sostiene que queramos y busquemos imitarnos abiertamente; al contrario, nos sentimos más valiosos al creernos únicos y diferentes, pero la manera más efectiva de hacerlo es engañándonos a nosotros mismos, olvidándonos de que gran parte de lo que somos lo hemos recibido de otros a través de una imitación muy "atenta" de sus comportamientos. Un efecto de esto, no siempre tenido en cuenta, es que cuanto más nos convencemos de que la información que nos constituye ha emanado de nuestra interioridad y es cosecha nuestra, más nos ponemos territoriales, defensivos y agresivos con ella. Por eso la imitación desemboca, de manera muy difícil de evitar, en el conflicto.

La mímesis, como una imitación inconsciente y desapercibida, nos permite constituirnos y permite la transmisión simbólico-cultural en las sociedades humanas. Pero vemos cómo al mismo tiempo nos arroja al conflicto y la rivalidad. Tiene una cara luminosa y otra oscura. Es productora, pero también nos lleva a las peores y más violentas pasiones: la competencia violenta, la envidia, el resentimiento, los celos, complejos de inferioridad.

Esta dinámica aplica, según Girard (1985), para todos los individuos y culturas. Es un hecho estructural, un rasgo antropológico universal, aunque con variaciones en su intensidad. Estas dependen, como dijimos, del grado de proximidad entre individuos, y este a su vez depende del grado de igualitarismo o jerarquía del sistema sociopolítico, así como de las tecnologías disponibles para los fines de comunicación y transporte. La distancia vertical entre estratos o estamentos sociales, o entre modelos apartados en el tiempo y la distancia, así como la ausencia de tecnologías de acercamiento, garantiza de alguna manera un tipo de mediación externa, quedando con ello disminuidas las posibilidades de deseo-imitación entre unas personas y otras. En las sociedades igualitaristas y horizontales, y con mayores tecnologías de acercamiento, la proximidad de unos y otros hace que el deseo se propague más intensa y uniformemente, alimentando aún más el deseo de diferenciación. La mediación 
interna nos hace más visibles unos para los otros, pero también hace que afloren violencias psicológicas inusitadas.

Para Girard (1985) resulta fundamental reconocer el hecho de la presencia del mediador en la constitución de nuestros deseos y por lo tanto de nuestra interdividualidad. De no hacerlo, nos vemos presas de sentimientos conflictivos y de rivalidad; además nos hace proyectar una sombra de ignorancia sobre nosotros mismos y sobre los demás. Muchos de los más grandes escritores de todos los tiempos lograron comprenderlo después largos sufrimientos, luego de una experiencia radical que Girard no dudó en llamar “conversión”, tras reconocerse humildemente como esclavos del mimetismo (Girard, 1985). Esta comprensión funciona como una verdadera liberación, la cual desencadena energías creativas que de otro modo quedarían represadas o debilitadas. Nombres como Shakespeare, Cervantes, Stendhal, Flaubert, Proust y Dostoyevski, fueron luminarias que lograron plasmar en su literatura una comprensión sorprendente sobre las problemáticas psicológicas y sociológicas del ser humano, en cierto sentido mucho más fina que la de la filosofía y las ciencias sociales. Girard nos ayuda a entender la universalidad y atemporalidad de sus aportes.

\title{
América Latina y su circunstancia no hegemónica: una historia frente al otro
}

\author{
No se debería comer sin compañía. \\ -Evando Nascimento
}

La sociedad contemporánea se muestra obsesiva en estimular en los individuos la originalidad y la innovación absolutas. Copiar, reproducir, imitar, no vende, no fascina, no atrae. Reconocer las influencias, aceptarnos como un eslabón más de una larga cadena, no satisface nuestro apetito narcisista. Ser humildes frente a la tradición no acalla nuestras ansias por sobresalir.

Buena parte de los bloqueos de nuestra historia cultural latinoamericana se puede entender si exportamos este modelo individual a un plano social, si como dice Rocha, pasamos de lo interdividual a lo interdividual colectivo. Nuestra autocomprensión ha estado atravesada y sigue habitada por la formulación de un falso dilema respecto de nuestros modelos prestigiosos, encarnados por los centros de poder que alguna vez nos 
sometieron -quizás aún nos siguen sometiendo- política, cultural y económicamente. Este falso dilema ha recibido muchas formulaciones, las cuales exhiben distintos grados de radicalidad. En términos socioeconómicos, ha sido quizá la más conocida la que clama la necesidad de elegir entre dos caminos de desarrollo: "dependencia" o “autonomía”. En términos político-culturales, el gran pensador Fernando González lo expresó bajo la distinción entre "vanidad” y "personalidad” o "egoencia”"

Miradas en clave girardiana, este tipo de dicotomías tajantes son fruto de un profundo autoengaño denominado mentira romántica. En el plano interdividual colectivo que nos atañe la mentira se hace más patente, pues se refiere a una realidad histórica en la que nuestros pueblos y tradiciones inevitablemente han tenido una prolongada convivencia frente a otros que nos han contagiado miméticamente de un modo que quizás aún no hemos comprendido del todo.

El hecho justificado de que nos molesten los procedimientos injustos e inhumanos mediante los cuales lo europeo colonial, y luego lo estadounidense neocolonial, nos han sido impuestos, no hace menos real la implantación de los valores de esos otros en el seno mismo de lo que somos. Ni tampoco obliga a reducirlos únicamente a sus aspectos deleznables. Y aunque nos moleste sobremanera, estos mediadores han funcionado muy fuertemente como modelos admirados, unos otros de cuyo ser hemos querido, consciente o inconscientemente, apoderarnos. Debemos contar con ello.

Por razones dolorosas, sí, reconoce Rocha que los latinoamericanos tenemos todo para ser especialmente conscientes de la "presencia insoslayable del mediador en la constitución de la propia identidad” (2014, p. 146), de aquello que Girard llamó la verdad novelesca. Nuestras culturas, al sufrir una relación asimétrica en las relaciones

1 En una obra de 1936, que tiene un interés primordial en tanto acomete un examen que podriamos denominar mimético de las culturas americanas y de sus naciones, razas y gobernantes, caracterizándolas según sus hábitos de imitación, González formula un esquema de comprensión que cae en la separación tajante de dos fenómenos que para la teoria mimética no conviene separar tanto. Así, para el filósofo colombiano la vanidad se define como "vacío", "simulación", "carencia de sustancia", "hurto de cualidades para ser considerado socialmente". Los actos propios de la vanidad serian centripetos, revelarian una "ausencia de motivos intimos, propios", una "hipertrofia del deseo de ser considerado". La personalidad o egoencia, en cambio, se define como "individualidad", "autoexpresión". Y sus actos serian "centrífugos", fruto de "intima determinación", "auténticos". Otra noción importante de este autor es la del "complejo de hijo de puta", que consiste en la simulación vergonzante que prefiere asumir lo impropio, por la pena de abrazar lo propio, arbitrariamente considerado indigno o inferior. Por último, también contrapone "educación" como repetición a "creación" como innovación (González, 1976). 
geopolíticas de poder, tienen mayor capacidad de deconstruir la pretendida pureza con la que toda cultura enmascara sus orígenes miméticos y violentos. No obstante, se trata de una ventaja que poco hemos sabido aprovechar, puesto que no la hemos visto como tal, con la excepción de unos cuantos: una minoría que ha sido sorprendentemente, y quizás debido a ello, conformada por las más grandes y universales figuras de la cultura latinoamericana. Rocha menciona que lo han sabido capitalizar más los artistas y escritores, y menos los teóricos y pensadores (2014, p. 153).

Frente a esta problemática muchas corrientes latinoamericanistas se posicionaron esgrimiendo la necesidad de romper violenta y definitivamente los lazos que nos unían con los conquistadores y colonizadores, buscando recuperar una supuesta esencia perdida, sea volcándose a la búsqueda de identidades autóctonas, consideradas primigenias, o buscando crear de ceros una nueva tradición, desde un pretendido aislamiento. Una y otra empresa no deja de ser más que formas de autoengaño, de mentira romántica, y se han revelado por ello bastante estériles. La teoría mimética nos da luces para comprender por qué.

Un campo de batalla en el que esto aparece sumamente claro es precisamente el de la historia cultural. Para Rocha, la universidad y el estado-nación modernos, tras los procesos políticos de independencia, patrocinaron la mentira romántica de la "identidad nacional", esforzándose por autoreconocer lo constitutivo de cada pueblo latinoamericano en una suerte de "reapropiación de lo propio", en el entendimiento de que esto "propio" era una suerte de esencia pura, violenta y traumáticamente desapropiada por la invasión extranjera. Así, la historia cultural desea aparecer como "el momento pleno, conscientemente narrado, del encuentro re-flejado del ser con sus atributos intrínsecos” (Rocha, 2014, p. 89). ¡Se debe tener mucho cuidado con ella!

Más allá de esta visión ingenua, o quizás cínicamente violenta, pues este tipo de narrativas necesariamente se aplican con el costo de una eliminación de las diferencias internas que escapan al discurso de una identidad nacional determinada a priori, los grandes pensadores latinoamericanos acogieron otro tipo de aproximación frente a la búsqueda de lo propio. Una que pasa necesariamente a través de lo ajeno, incorporándolo y asimilándolo activamente, sin negar por ello sus aspectos problemáticos.

Así, uno de los mayores aportes de la propuesta de Rocha es que logra visibilizar la existencia de un campo semántico común, que acerca y pone en diálogo distintas terminologías acuñadas por latinoamericanos de diversas nacionalidades, que 
con palabras distintas indican un mismo fenómeno: la inevitabilidad de llegar a imágenes de uno mismo a través de los ojos del otro, y el beneficio que se extrae de ello en cuanto a la calidad y potencia de dichas imágenes. La formulación quizás más explícita y conocida de esta estrategia podría ser el "canibalismo cultural" del brasileño Oswald de Andrade (1928), pero hay muchos otros casos similares, como la comprensión de la cultura como síntesis hecha por Pedro Henríquez Ureña (Tena y Castro, 2001). Para el intelectual dominicano resulta un error tan fehaciente que los americanos pretendamos sostener la creencia de una cultura puramente autóctona que menosprecie la tradición europea, como que desdeñemos ciertas raíces nativas acogiendo ciegamente el europeísmo.

Los grandes autores latinoamericanos no han caído en la trampa de una construcción de la identidad bajo el dilema de influencia vs autonomía, imitación vs. innovación, o influencia vs. originalidad. Ellos distinguen dos tipos de posicionamiento frente a la inevitabilidad de la presencia constitutiva de la alteridad en la construcción inacabada de un ser postergado e inestable. Se trata de algo muy evidente en pueblos caracterizados, según la terminología del mexicano Eugenio O'Gorman, por una determinación ontológica ab alio, una identidad como grieta o fractura en permanente inestabilidad que es resultado de violentos procesos de conquista exterior (Roig, 1981).

No se trata entonces de escoger entre si se continúa sin más la tradición, o si se mantiene esta aparte como en una especie de cuarentena. Se trata de qué tipo de posicionamiento estratégico se tiene frente a ella, aceptando que a través de sus ojos nos reconocemos de una manera muy interesante. Volviendo a Henríquez Ureña, este distinguió entre una imitación "difusa" y otra "sistemática", siendo la primera la yuxtaposición caótica de elementos extranjeros, y la segunda la composición compleja e inteligente de elementos heterogéneos, que crea novedades dentro de condiciones preexistentes. Para complementar con otros ejemplos de los usados por Rocha, mencionemos al mexicano Antonio Caso, quien habló de una imitación negativa, valorada así por ser ciega, pasiva y mecánica, la cual denominó “extralógica". El humor popular a veces puede expresar con elocuencia algunos destellos de conciencia acerca de esta forma ciega y estéril de imitación, deconstruyéndola rudimentariamente, en la medida en que la somete a una distancia crítica incipiente. Un extendido chiste colombiano relata cómo en nuestro país las clases populares y trabajadoras se comportan y buscan verse como mexicanos, la clase media como estadounidenses y la clase alta como ingleses. Y los intelectuales como franceses. 
El cubano Fernando Ortiz, por su parte, acuñó el término de “transculturación”, una compleja apropiación cultural en la que, al tiempo que se recibe, se aporta algo (Matos, 1998). En cambio, la “aculturación” aparece como la aceptación conformista de la imposición de valores culturales extranjeros. También podríamos incluir al mexicano José Vasconcelos (1948) y su planteamiento de la "raza cósmica”, noción curiosamente ignorada por Rocha en su extenso libro, pero que perfectamente cabe dentro de los referentes trabajados por él, puesto que en dicho concepto se busca valorar el producto de la mezcla y el contagio cultural.

Rocha propone entonces trasladar la comprensión girardiana de la constitución triangular de la interdividualidad subjetiva -mediada a través de otros, modelos problemáticos en tanto nos fascinan y nos indican qué y cómo desear, a la vez que obstaculizan la consecución de esos deseos interponiéndose entre esos objetos y nosotros- a la constitución de las interdividuales colectivas, de pueblos y culturas.

Con ejemplos muy sugerentes de experiencias constitutivas de la nacionalidad que son producto de este movimiento de rodeo a través del otro, analiza Rocha un par de rasgos que, con orgullo, los brasileños sostienen que constituyen su aporte propio y local al mundo. Lo que nos muestra es que, como fruto del desconocimiento de su deuda con lo ajeno, se convierten en mitologías encubridoras. Se trata de: 1) el mestizaje como contribución a la civilización moderna, 2) el proyecto de representación de la naturaleza tropical como marca distintiva de su literatura romántica, y 3) la fundación de la más importante universidad brasileña, la USPE. Para sorpresa de quien no tenga suficiente familiaridad con la historia de este país, una mirada escudriñadora muestra que el primero fue sistematizado por un alemán, Philipp von Martius, en atención a un concurso establecido por el emperador de Portugal Pedro II en 1843; el segundo fue bosquejado por el francés Ferdinand Denis en la década de los años 20 del siglo XIX; y la última, fue fundada por una misión francesa en 1934. Resultan de miradas e iniciativas extranjeras que, efectivamente, ayudaron mucho a que los brasileños pudieran interesarse por ellos mismos a través de tales mediaciones, y más adelante pasaran a ser elementos configuradores de lo propio. Lo importante es la claridad que pueda haber sobre su origen, que en parte determina su destino y uso político.

Para el caso colombiano podrían rastrearse ejemplos similares, y podemos citar dos: 1) la Expedición botánica y 2) la Misión corográfica, empresas de recolección de datos de la naturaleza neogranadina con el objetivo de adelantar un sistemático 
reconocimiento de elementos constitutivos de la identidad nacional, que se ha señalado fueron muy importantes en la construcción de una idea de lo propio y en el caso del primero, incluso inspirador de las ideas de independencia. Sin embargo, examinándolos de cerca, nos encontramos con que la primera versión de la expedición botánica fue inspirada y dirigida por la figura del naturalista español José Celestino Mutis hacia 1783, y la primera edición de la comisión corográfica por el geógrafo italiano Agustín Codazzi hacia 1850. Es decir, fenómenos nacionalísimos dependían en alto grado de elementos foráneos.

Tenemos entonces, según Rocha, dos efectos y condiciones fundamentales de lo mimético en la historia cultural e intelectual de Améria Latina. Primero, una dialéctica entre localismo y cosmopolitismo, por la cual lo ajeno se transforma en propio. Esta exige una perspectiva comparada para ser comprendida y aprovechada en todo su potencial, pues el tránsito constitutivo entre tradiciones diversas se ha mostrado como un paso fundamental en la invención de una literatura propia, la cual aparece ante el mundo como resultado de la conjugación entre el corpus de la civilización occidental en su conjunto, sumado a los aportes que resultan de las condiciones singulares de las realidades de cada país latinoamericano. En segundo lugar, se revela por fin un potencial enorme para revelar la mentira romántica de la identidad nacional, la cual da alas a proyectos nacionalistas y aislacionistas, responsables de movilizar los ánimos a través de la remisión a símbolos comunes que funcionan para ciertas colectividades sobre la base de la diferenciación, es decir, pretendiendo la construcción ficticia de una diferencia absoluta que requiere distinguir entre amigos y enemigos, generando exclusiones, periferias dentro de la periferia y hasta desplazamientos y exterminios colectivos.

Pasemos a tres ejemplos más señalados agudamente por Rocha para entender por fin en qué consiste la tipología de "culturas shakespearianas" y por qué responden a un mismo principio estructural. En 1931, en América ante la literatura joven, el cubano Alejo Carpentier habla de cómo:

Todo arte necesita de una tradición de oficio. En arte la realización tiene tanta importancia como la materia prima de una obra... [...] Por ello es menester que los jóvenes en América conozcan a fondo los valores del arte y la literatura moderna en Europa [...] para tratar de llegar al fondo de las técnicas, por el análisis y hallar métodos constructivos aptos a traducir con mayor fuerza nuestros pensamientos y [...] sensibilidades de latinoamericanos... Diego Rivera, 
hombre en quien palpita el alma de un continente, nos dice: "Mi maestro, Picasso". (Citado en Rocha, 2014, p. 67)

Así mismo, un joven García Márquez escribe hacia 1950, en El Heraldo de Barranquilla, en un texto llamado ¿Problemas de la novela?:

Todavía no se ha escrito en Colombia la novela que esté indudable y afortunadamente influida por los Joyce, por Faulkner o por Virginia Woolf. Y he dicho "afortunadamente" porque no creo que podríamos los colombianos, ser, por el momento, una excepción al juego de las influencias. En su prólogo a Orlando, Virginia confiesa sus influencias, Faulkner mismo no podría negar la que ha ejercido sobre él el mismo Joyce [...]. Si los colombianos hemos de decidirnos acertadamente, tendríamos que caer irremediablemente en esta corriente. Lo lamentable es que ello no haya acontecido aún, ni se vean los más ligeros síntomas de que pueda acontecer alguna vez. (Citado en Rocha, 2014, p. 66)

Por su parte Borges lamenta hacia 1941, en el prólogo a su Antología poética argentina, la pospuesta falta de universalidad de la cultura latinoamericana: "A diferencia de los bárbaros Estados Unidos [...] este continente no ha producido un escritor de influjo mundial -un Emerson, un Whitman, un Poe-, ni tampoco un gran escritor esotérico: un Henry James, un Melville” (citado en Rocha, 2014, p. 121).

Lo maravilloso es que estos autores, los dos primeros exactamente 17 años después, y el tercero 25 años después, y cuya calidad llegaría a ser indiscutible -todos merecedores del premio Nobel de literatura - al ver que sus reclamos no habían sido atendidos, se convierten en dichos autores de dimensión mundial. ¿Cómo lo hicieron?

La respuesta a esta pregunta toca el corazón de la propuesta de Rocha: la comprensión de que el procedimiento de los grandes autores latinoamericanos apela a un modelo retórico olvidado por el romanticismo y que podría denominarse "poética de la emulación". En él no hay un choque con la tradición sino un interés valorativo hacia ella que parte de la imitatio de una serie de auctoritas, reconocidas por su arte, por un manejo de unas técnicas. Esto lleva, a través de una actitud de respeto y humildad, hacia una aemulatio, mediante la cual el discípulo desarrolla su propio estilo y logra innovar y a veces superar a sus maestros. 
El concepto de "culturas shakespearianas" emana precisamente de este modelo. Rocha se refiere al autor de La tempestad por un rasgo que pasa desapercibido para la mentira romántica de nuestros manuales de historia literaria: más que ser un genio creador exnihilo, Shakespeare fue un activo "copión", un incorporador voraz de todo aquello que el pasado pudiera proveerle para la realización de sus obras. En palabras de Rocha:

\begin{abstract}
Shakeaspeare es importante no solo por los temas con los cuales trabajó sino, y sobre todo, por su procedimiento compositivo, esto es, la constante apropiación de lo ajeno en la producción de su obra. De hecho, en la casi totalidad de sus piezas no se preocupó en desarrollar una idea "original", pero siempre supo aprovecharse del material ya existente, combinando fuentes distintas en una forma, eso sí, única. (Rocha, 2014, p. 91)
\end{abstract}

De 37 piezas que componen su teatro, 33 reflejan la recomposición, el bricolaje sobre otras obras. Se trata, más que de creaciones -utópicas e idealizadas-, de invenciones -realistas-. Girard mismo menciona cómo la palabra "innovar" refiere más bien la recreación de algo, el renovar de una forma preexistente, más que la creación a partir de la nada. De ahí que tuvo un marco semántico teológico que se trastocó hacia el siglo XVII con el desarrollo del individualismo, con el ascenso del prestigio social de la ciencia nueva, y con la secularización (Girard, 1990, pp. 7-20).

Eran estas fuentes no solo clásicas, sino contemporáneas, es decir, muy heteróclitas entre sí, pero el genio de Shakespeare está en haber hecho de esa heterogeneidad un conjunto complejo, pero sobre todo coherente. Y bueno, esto explica por qué grandes obras de la conciencia latinoamericana, como Ariel del uruguayo José Enrique Rodó (1900) y Calibán del cubano Roberto Fernández Retamar (1971) se han identificado fuertemente con el escritor inglés con quien aparentemente no tenían mucho que ver.

La poética de la emulación es entonces un ars combinatoria, una estrategia no hegemónica de transformar la precariedad en una ventaja. En la circunstancia no hegemónica, los pueblos latinoamericanos han sufrido una "condición de secundidad", pero muchos, lejos de paralizarse o acomplejarse por este hecho, lo han transformado en el núcleo mismo de sus fuerzas creativas, o para ser más fieles a la terminología de la emulación, de sus fuerzas inventivas. Los latinoamericanos hacen posible el lema bíblico de que "los últimos serán los primeros". Hacen que de la retaguardia surjan inesperadas vanguardias. 
La situación de opresión cultural y de asimetría en el mercado simbólico mundial nos ha obligado a los latinoamericanos a mantenernos en una ambigua relación frente a los centros de poder. En tanto modelos fascinantes, nos apropiamos de sus capitales culturales -que también son en parte los nuestros- en una especie de ansiedad mimética. Aprendemos segundas, terceras y hasta cuartas lenguas, no solo modernas sino antiguas; manejamos las bibliografías y los referentes teóricos de actualidad; tenemos un conocimiento histórico y geográfico de culturas que no son exactamente aquellas en las que vivimos; ensanchamos todo el tiempo nuestro repertorio de referencias y marcos teóricos y deseamos ocultamente hacer parte de los centros que mandan la parada en términos de dirección de las tendencias hegemónicas. Pero al mismo tiempo, constantemente estamos contrastando modelos ajenos con singularidades distintas y locales; hacemos dialogar tradiciones y temporalidades muy heterogéneas; yuxtaponemos problemáticas distintas; disponemos de material raro y marginal. Darle una forma consistente y lógica a todo esto es muy difícil, pero incita un espíritu crítico inusitado y suscita una actitud de irreverencia frente a tradiciones puristas, desencadenando una flexibilidad en la escritura y en el pensamiento.

Un último ejemplo de Rocha nos ayuda a comprender la dificultad y a la vez las posibles bondades que podemos extraer de un hecho en parte estructural -el mimetismo del deseo- y en parte histórico -la situación de no hegemonía-. Domingo Faustino Sarmiento, el intelectual argentino, se veía en la dificultad de vender el diario El progreso en Chile durante su exilio, puesto que su competencia eran diarios europeos de renombre cuyas noticias estaban muy frescas y reflejaban las opiniones prestigiosas de los intelectuales más importantes de los centros de la cultura. En primer lugar, aprovechó la posibilidad de brindar materiales en las lenguas locales, además brindando una selección realizada por él. Se trataba entonces de materiales ya depurados, que reunían los mejores artículos, los más relevantes y los más sugerentes, según el discernimiento de la inteligencia de Sarmiento. Se trataba demateriales sobre los que ya había operado un primer nivel de interpretación, por así decir (Rocha, 2014, pp. 139-140).

Nuestra capacidad de competencia en una situación en la que de entrada estamos un poco marginados, como latinoamericanos, de los principales códigos de producción, difusión, distribución y consumo simbólico y cultural, nos exige acudir a estrategias particulares para poder estar a tono en el diálogo internacional. Rocha cree que la poética de la emulación nos brinda esta oportunidad, pero para poder aprovecharla debemos comprender los mecanismos de funcionamiento del deseo, no caer en la 
mentira romántica tanto de idolatrar a nuestros modelos como de creernos arrogantemente autosuficientes y separados de ellos. La eliminación de la alteridad nos incapacita para enriquecernos con ella, pues en ella el otro hace las veces de un espejo que nos permite observarnos mejor, al reflejarnos en él.

Igualmente, se muestra como una tarea urgente la necesidad de mirar con "los ojos bien abiertos", puesto que a nuestro alrededor existen sujetos muy capaces y suceden todo el tiempo cosas maravillosas que a veces no vemos, por subestimar nuestras capacidades y las de nuestros pares, y que son las que a menudo maravillan a los extranjeros como noticias fabulosas de tierras extrañas, otorgándoles el valor que nosotros no sabemos darles. Como dijo Fernández Retamar (1995), No es que no hubiéramos dado aportes universales a la cultural, sino que no se habían exportado ${ }^{2}$.

Acabemos este pequeño aporte con una cita de uno de los grandes escritores de todos los tiempos, que parece pensada para la precariedad de las culturas que han sido víctimas de opresión cultural:

La mejor salsa del mundo es la hambre; y como esta no falta a los pobres, siempre comen con gusto.

-Cervantes, en boca de Teresa Panza

\section{Referencias}

De Andrade, O. (1928). Manifiesto Antropófago. Revista de Antropofagia, 1(1). Recuperado de http://fama2.us.es/earq/pdf/manifiesto.pdf

Díaz, J. M. (2010). Elementos para la reconstrucción de una filosofía de la historia en René Girard. Universitas Philosophica, 27(55), 75-91.

Echeverría, I. (2015). Decolonialización epistémica. Aportes del pensar andino abyayalanse a la filosofía. Cuadernos de Filosofía Latinoamericana, 36(113), 45-60.

2 Como parte de la postura de sostener la importancia de tener en cuenta lo que pasa en nuestras tierras y tratar de valorarlo, Rocha ha presentado un examen reciente de la recepción de la teoría mimética en nuestra región, identificando autores, bibliografías y líneas de trabajo. Todo esto es sumamente importante a la hora de crear una comunidad epistémica sólida y con referentes comunes, algo que nos falta (Rocha, 2014, pp. 75-120). 
Girard, R. (1985). Mentira romántica y verdad novelesca. Barcelona: Anagrama.

Girard, R. (1990). Innovation and repetition. SubStance, 19(2/3), 7-20, Issue 62/63. Special Issue: Thought and Novation.

González, F. (1976). Los negroides. (Ensayo sobre la Gran Colombia). Medellín: Bedout.

Fernández R., Roberto. (1995) Para una teoría de la literatura hispanoamericana. Bogotá. Instituto Caro y Cuervo.

Matos, J. (1998). Culturas híbridas. Fernando Ortiz: la historia en una perspectiva transcultural. Cuadernos de Literatura, volumen IV, números 7-8. Enero-Diciembre.

Meza, G. (2016). El 'vivir nosotros' amerindio vs. 'decir nosotros' de la globalización. Cuadernos de Filosofía Latinoamericana, 37(114), 151-166.

Nakajima, B. (2017). El concepto de cultura en los fundadores de la filosofía latinoamericana. Cuadernos de Filosofía Latinoamericana, 38(116), 73-95.

Rocha, J. C. (2014a). Apuntes iniciales sobre la interdividualidad colectiva. Por una recepción creativa de la teoría mimética en América Latina. (Sin publicar, 24 páginas).

Rocha, J. C. (2014b). ¿Culturas Shakespearianas? Teoría mimética y América Latina. Guadalajara: Cátedra Eusebio Francisco Kino.

Rocha, J. C. (2010). Historia cultural latinoamericana y teoría mimética: ¿Por una poética de la emulación? Universitas Philosophica, 27(55), 105-121.

Rocha, J. C. (2014c). Mimetic Theory and Latin America. Reception and Anticipations. Contagion: Journal of Violence, Mimesis and Culture, 21, 75-120.

Roig, A. (1981). Teoría y crítica del pensamiento latinoamericano. México D. F.: Fondo de Cultura Economica.

Tena, J., y Castro, T. (Comp.). (2001). Presencia de Pedro Henríquez Ureña. Escritos sobre el maestro. Santo Domingo: Editorial Ciguapa.

Vasconcelos, J. (1948). La raza cósmica. México, D. F.: Espasa Calpe. 